\title{
Cutting Forces in Drilling Operation: Measurement and Modeling for Medium-scale Manufacturing Firms
}

\author{
Gurumukh Das \\ Department of Mechanical Engineering \\ Faculty of Engineering \\ Dayalbagh Educational Institute, Agra, INDIA
}

\author{
Padam Das \\ Department of Mechanical Engineering \\ Faculty of Engineering \\ Dayalbagh Educational Institute, Agra, INDIA
}

\begin{abstract}
Advanced manufacturing systems often caters to rapidly changing product specification determination by the continuously increasing productivity, flexibility and quality demands. The estimation of cutting forces is mandatory to select tools and accessories for machining. Complex interrelationships exist between process parameters and these forces. In the present work, the applicability and relative effectiveness of artificial neural network based model has been investigated for rapid estimation of cutting forces. The results obtained are found to correlate well with the actual experimental readings of cutting forces. Experiments were conducted at different process parameters of cutting in Drilling operation. The proposed work has wide application in selection of tools and online tool wear monitoring.
\end{abstract}

\section{General Terms}

Measurement and modeling of Cutting forces.

\section{Keywords}

Drilling; Cutting forces; Cutting process parameters; Artificial neural networks (ANNs).

\section{INTRODUCTION}

The research in the area of metal cutting and machine tool is a fascinating experience. The Machining process is generally adopted to get higher surface finish, close tolerance, and complex geometrical shape that are otherwise difficult to obtain. The main problem is that all the manufacturing processes available for metal removal are probably the most expensive one. This is because of the substantial amount of metal removal taking place from the raw material in the form of chips in order to achieve the required shape. A lot of heat energy is generated in the process of metal cutting which is another reason for expensiveness of the process [1].

In the market with an increased demand for quality manufacturing along with the short lead time and short product life cycles, the increasing consumer awareness always looks for the cost factor and quality so this becomes most important for the manufacturers to take some initiative steps. To achieve all these, some questions arise in the mind of a production engineer: 1) Which is the most suitable and economical tool for a particular metal cutting operation? 2) For what specification, power consumption is minimum? 3) How much heat is generated in the metal cutting process? 4) What type of coolant should be used? 5) What should be the optimal flow rate of coolant? etc. To answer all these questions, the estimation of cutting forces is a must [2].

In the world of manufacturing, everyone is stressing on the need of fast accessing the information related to tool management systems i.e. providing the right tool at the right place and at the right time. If there is dedicated transfer line, it will be sufficient to determine the tool with required strength at the beginning of the machining, but in batch-type production having no flexible manufacturing system and any advanced information facilities, it will not be possible for a production engineer at work floor to determine the necessary tool with sufficient strength for a new job settings (in terms of changed operational parameters and work material). This situation compels him to go to either production planning and control (PPC) department or tool design department. This whole cycle makes the manufacturing systems sluggish and cumbersome [3].

Besides this, what happens sometimes is that at the production floor, there may be frequent and slight changes of work material, process and process parameter then every time production engineer will have to contact to the above departments. This results into a large non-productive time of machine tool as well as worker's idle time, most of the times resulting into production halt [4].

To avoid this situation, the trained neural network (NN) model can be made available on a computer located at the production floor itself to production engineers for estimation of cutting forces. They can give the inputs to NN model in the form of process parameters, type of work material, etc. By doing so, with no lapse of time they will get all cutting forces acting on the tool in real time situation and matching the values of these forces with tool handbooks, they can choose the tool with required strength, which can perform operation satisfactorily [5-6].

It solves the most of the complications of production engineer's job and a lot of non-productive time can be saved. This system becomes an essential part of production system especially in those, where every department is not integrated through a software system to access information from one department to another rapidly. It will work well in mediumscale manufacturing industries [7].

\section{LITERATURE REVIEW}

Modeling can be said to have had its beginning as an organized process in the late 1890 s to early 1900 s originated with F.W. Taylor's pioneering engineering research and development of empirical methodology (and equations) for estimating reasonably economic machining conditions. Science-based modeling began to emerge in the 1940 s by Merchant's physics-based modeling in a machining process. Computer-based modeling, the "watershed" event of the advent of digital computer technology and its application to manufacturing in general, was started in the 1970s [8]. 
Osman, Xistris and Chahil (1979) made the measurement and analysis of torque and thrust in drilling mild steel with twist drills using a specially designed two-component piezoelectric dynamometer which was both statically and dynamically calibrated [9].

Koplev, Lystrup and Vorm (1983) examined the cutting of unidirectional CFRP, perpendicular as well as parallel to the fiber orientation. They measured cutting forces parallel and perpendicular to the cutting direction for various parameters, and correlated the results to the formation of chips and the wear of the tool [10].

Veniali, Di Llio and Tagliaferri (1995) experimentally investigated major drilling characteristics of Aramid fiberreinforced plastics. The chips appeared were found to be highly deformed and tend to smear on the tool and the forces and torque to be more influenced by the tool diameter than by the feed rate and cutting speed [11].

The object of the study by Fuh and Wang (1997) was to model and forecast the grinding force for the creep feed grinding process, using error distribution function based backpropagation neural network improved [12].

To model drilling processes, Lee, Liu and Tarng (1998) described the use of an abductive network composing of a number of self-organized functional nodes by means of a predicted squared error criterion. They predicted the drilling performance in terms of tool life, metal removal rate, thrust force and torque using above network. A simulated annealing technique with a performance index was then applied to optimize process parameters [13].

Szecsi (1999) proposed a method for cutting forces modeling using multi-layer feed-forward back-propagation neural networks trained by the experimental machining data for simulating and defining the cutting forces in the process [14].

Elhachimi, Torbaty, Joyot (1999) presented a new theoretical model to predict thrust and torque in high speed drilling. This technique was consisted of continuous measurement of cutting forces on the twist drill [15].

Lachaud, Piquet, Collombet and Surcin (2001) gave a model linking drill-bit axial penetration in terms of thrust force [16].

Ramulu, Branson and Kim (2001) experimented with variety of drill-bit materials to perform holes on graphite / bismaleimide titanium work with a standard geometry. The purpose was to understand and characterize the process [17].

Zuperl and Cus (2004) used ANN technique to find out the cutting forces for ball-end milling operation and to compare predictability ANN and analytical techniques [18].

Sheng and Tomizuka (2006) proposed an intelligent technique to model cutting forces in drilling process. For that, NN models were developed [19].

The principal aim of the work done by Abrão, Faria, Campos Rubio, Reis and Paulo Davim (2007) was to perform a survey on the machining of composite materials [20].

Aykut, Gölcü, Semiz and Ergür (2007) used scaled conjugate gradient feed-forward back-propagation neural network approach to model the effects of machinability on cutting parameters for face milling of stellite 6. [21].

Tsao and Hocheng (2008) presented the prediction and evaluation of thrust force and surface roughness in drilling of composite material using candle stick drill. The objective of this study was to establish a correlation between the feed rate, spindle speed and drill diameter with the induced thrust force and surface roughness in drilling composite laminate using RBFN [22].

\section{SELECTION OF MACHINE TOOL AND WORK MATERIAL}

In this work, we have selected a Radial Drilling Machine (installed at Machine Shop, Mechanical Engineering Workshop, Faculty of Engineering, Dayalbagh Educational Institute, Dayalbagh, Agra) as a machine tool. It is shown in Fig. 1. Specifically, Drilling machine is selected because it comes under the category of Primary machine tools as it performs primary functions but extent to which it can also be exploited to perform secondary functions. This is the most commonly used machine primarily designed to perform a variety of machining operations on a wide range of components. It is also known as a General purpose machine. By their nature of generalization, the general-purpose machines are capable to carry out a variety of tasks and the estimation of the cutting forces through these machines are also applicable to the production machine tools and the special purpose machine tools.

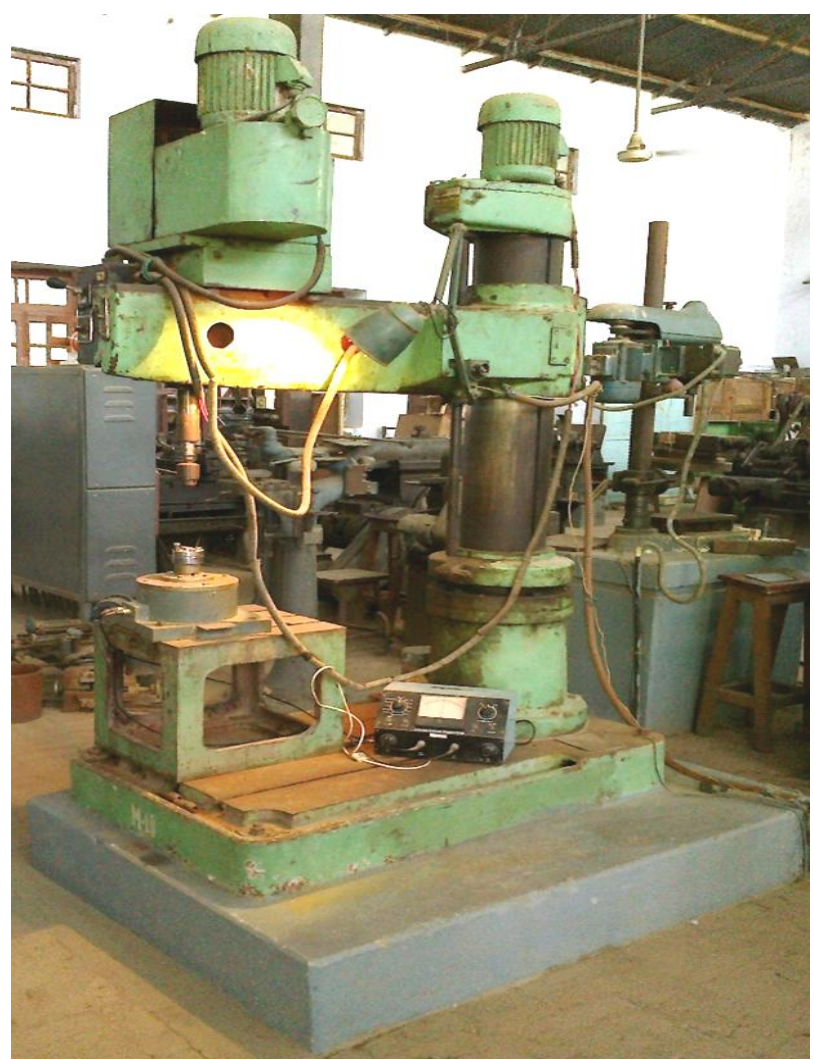

Fig 1: Experimental setup of Strain-gauge type Drillingtool dynamometer fitted on Radial Drilling Machine

The selection the work materials has been done out of a variety of engineering materials that are extensively used in the industries. These materials are used in the industries either individually or a combination of them is used. So, it becomes easier to estimate the cutting forces with the help of these materials for the large area of industrial materials. These materials are selected in this way that they cover wide range of yield strength from Mild steel to Aluminium. The five most commonly used materials selected for the experimentation are Mild steel (MS), Cast iron (CI), Copper ( $\mathrm{Cu})$, Brass, and Aluminium $(\mathrm{Al})$. 


\section{CUTTING FORCES}

To investigate the performance of drill bit during drilling process, the measurements of cutting forces are essential. This helps in analyzing: 1) the effects of speed and feed on the cutting action of the drill, 2) the effects of mechanical properties of work material on the drilling forces, and 3 ) forces exerted on Drilling machine parts, jigs and fixtures, and the effect of these forces on the dimensional accuracies of the drilled holes.

The force $\boldsymbol{R}$ acting on both the lips of drill in drilling process may be resolved into three mutually perpendicular force components: axial force $\left(\boldsymbol{F}_{\boldsymbol{A}}\right)$ along the axis of drill, radial force $\left(\boldsymbol{F}_{\boldsymbol{R}}\right)$ along the radial direction of drill, and tangential force $\left(\boldsymbol{F}_{T}\right)$ perpendicular to the force components $\boldsymbol{F}_{\boldsymbol{A}}$ and $\boldsymbol{F}_{\boldsymbol{R}}$.

Taking an ideal case of the drill with both the lips identical, the radial force components $\boldsymbol{F}_{\boldsymbol{R}}$ at both lips will get cancelled. Out of the remaining two components, axial components $\boldsymbol{F}_{\boldsymbol{A}}$ acting on both the lips will add to act as an axial thrust $\boldsymbol{P}$ on the drill; while the tangential components $\boldsymbol{F}_{T}$ acting on both the lips will form as a torque $\boldsymbol{M}$ opposing the rotation of the drill (see Fig. 2) [23-24].

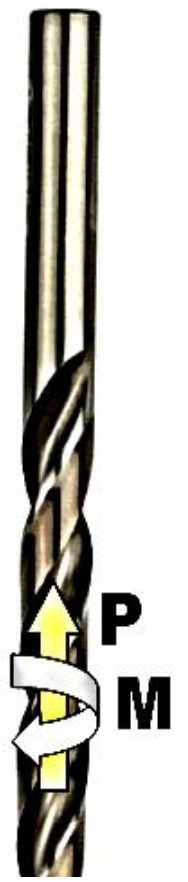

Fig 2: Resulting axial thrust and torque

\section{ARTIFICIAL NEURAL NETWORKS}

Back Propagation (BP) neural network is a multiple-layer network with one input layer, one output layer and some hidden layers between the input and output layers. Its learning procedure is based on a gradient search with least sum squared optimality criterion. Gradient is calculated by a partial derivative of sum-squared error with respect to weights. Input is given to ANN after assigning random initial weights, each neuron is computed, and weighted sum of inputs from preceding layer neurons is used as an input to succeeding layers. Towards the end, the weighted sum of networks is calculated [25-26].

A two-layer feed-forward network with three input neurons, eight neurons in the first hidden layer, six neurons in the second hidden layer, and two output neurons in the output layer is designed and trained with the LM learning rule. The logarithm and tangent of sigmoid functions are used in the hidden layers, and the output layer has a pure linear neuron (see Fig. 3). Fig. 4 shows the training graph between the sumsquared error and the number of epochs.

Spindle speed (in RPM), work material (numbered as 1 to 5 ) and Drill diameter (in $\mathrm{mm}$ ) are the three input parameters and output parameters are the resulting cutting forces, viz., torque (in $N-m$ ) and axial thrust (in $N$ ) [27]

\section{Drill Work Spindle}

Diameter Material Speed (in $\mathrm{mm}$ ) (numbered (in $R P M$ )

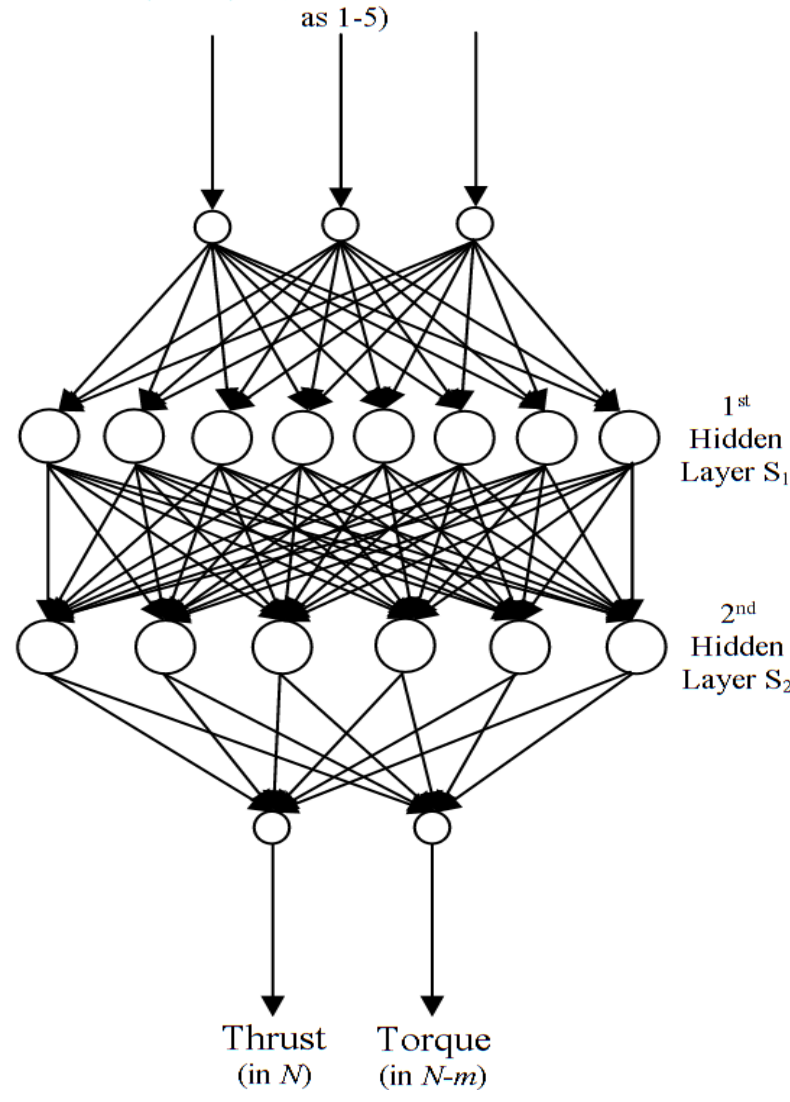

Fig 3: Neural network architecture

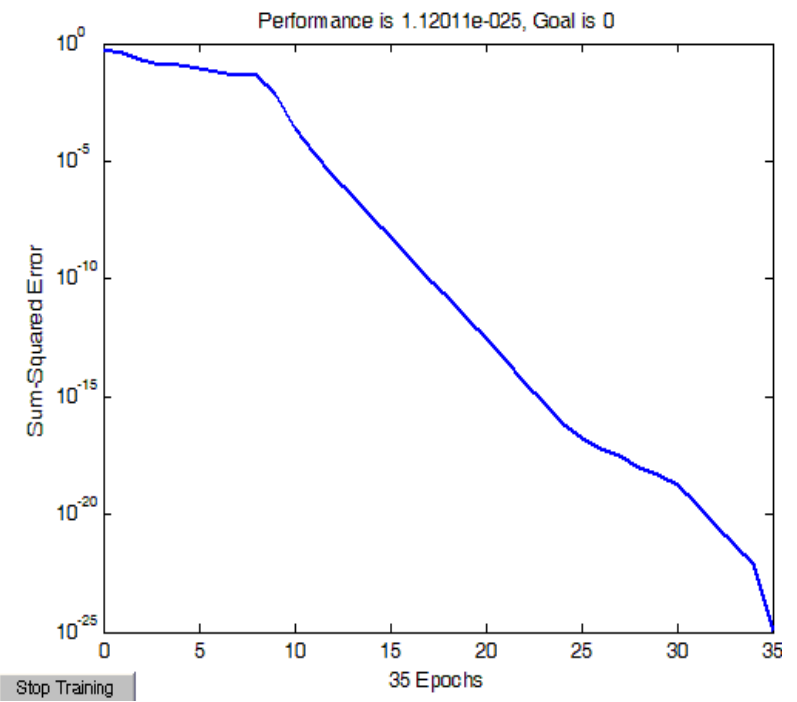

Fig 4: Training graph 


\section{EXPERIMENTAL SETUP AND DATA COLLECTION}

Drilling-tool dynamometer is essential to analyze the process of Drilling, as well as to solve the shop floor problems, such as, drill tool performance, forces on the machine parts, jigs and fixtures. To determine axial thrust and torque, drilling job is to be mounted over a fixture, which itself is mounted over the arms. The strain-gauges are mounted over arms to sense the load. The unit can be easily mounted over a table of drill machine. Dynamometer is calibrated for load up to $500 \mathrm{kgf}$ axial thrust and $10 \mathrm{kgf}-\mathrm{m}$ torque.

The Strain-gauge type Drilling-tool dynamometer consists of following sub-units:

\subsection{Sensing Unit}

The sensing unit consists of an armed wheel with straingauges cemented on the arms. The unit accurately senses the axial thrust $\boldsymbol{P}$ independently and feeds the output to bridge balance unit.

\subsection{Bridge Balance Unit}

The bridge balance unit consists of a regulated power supply used to supply power to both the bridge circuits and changeover switch SW-5 connecting one of the bridge output channels to the measuring unit at a time.

\subsection{Measuring Unit (DC Micro-voltmeter)}

A standard DC Micro-voltmeter used to measure voltages from $0.1 \mu V$ to $3 V$ is required to measure the output of bridge balance unit.

The strain-gauge readings, noted from the DC Microvoltmeter, are then converted into the actual cutting force values using the standard Calibration chart. The calibration relations for Strain-gauge type Drilling-tool dynamometer are as follow:

\subsubsection{Axial Thrust Conversion:}

3.8 micro-volts is equal to 1 kilogram force. This results into the following formula:

$$
P=V \times \frac{9.806}{3.8}=(2.58 \times V) N
$$

\subsubsection{Torque Conversion:}

145 micro-volts is equal to 1 kilogram force-meter. This results into the following formula:

$$
M=V \times \frac{9.806}{145}=(0.0676 \times V) \quad N-m
$$

Here, $\boldsymbol{P}$ and $\boldsymbol{M}$ stand for axial thrust and torque respectively. It is obtained by $\boldsymbol{P U 1}$ or $\boldsymbol{P U} \mathbf{2}$ channel readings indicated by the strain-gauges. For obtaining actual cutting forces, we have substituted $\boldsymbol{P U 1}$ and $\boldsymbol{P U} \mathbf{2}$ values including reference scale into the above conversion relations [28].
Table 1. Experimental values of axial thrust, $P$ measured at 110 RPM for different diameter drills and work materials

\begin{tabular}{|c|c|c|c|c|c|c|}
\hline \multirow{2}{*}{$\begin{array}{c}\text { S. } \\
\text { No. }\end{array}$} & \multirow{2}{\text{Drill}}{$\begin{array}{c}\text { Dia. } \\
\text { (in } \mathbf{m m} \text { ) }\end{array}$} & Axial thrust, $\boldsymbol{P}$ (in $\boldsymbol{N}$ ) for different work materials \\
\cline { 3 - 7 } & $\begin{array}{c}\text { Blum- } \\
\text { inium }\end{array}$ & $\begin{array}{c}\text { Cast } \\
\text { iron }\end{array}$ & $\begin{array}{c}\text { Mild } \\
\text { steel }\end{array}$ & Copper \\
\hline 1 & 12.0 & 980.5 & 903.1 & 1496.5 & 1092.1 & 1238.5 \\
\hline 2 & 11.0 & 774.1 & 774.1 & 1032.1 & 1063.6 & 1186.9 \\
\hline 3 & 10.2 & 774.1 & 774.1 & 903.9 & 1031.2 & 1135.3 \\
\hline 4 & 9.0 & 619.2 & 722.4 & 877.3 & 1002.3 & 1083.7 \\
\hline 5 & 8.0 & 541.8 & 722.4 & 774.1 & 990.1 & 1032.1 \\
\hline 6 & 7.0 & 464.4 & 696.7 & 722.5 & 980.5 & 1032.1 \\
\hline
\end{tabular}

Table 2. Experimental values of torque, $M$ measured at 110 RPM for different diameter drills and work materials

\begin{tabular}{|c|c|c|c|c|c|c|}
\hline \multirow{2}{*}{$\begin{array}{c}\text { S. } \\
\text { No. }\end{array}$} & \multirow{2}{*}{$\begin{array}{c}\text { Drill } \\
\text { Dia. } \\
\text { (in } \mathbf{m m} \text { ) }\end{array}$} & \multicolumn{4}{|c|}{ Torque, $\boldsymbol{M}$ (in $\boldsymbol{N}$-m for different work materials } \\
\hline 1 & 12.0 & 1.881 & $\begin{array}{c}\text { Alum- } \\
\text { inium }\end{array}$ & $\begin{array}{c}\text { Cast } \\
\text { iron }\end{array}$ & $\begin{array}{c}\text { Mild } \\
\text { steel }\end{array}$ & Copper \\
\hline 2 & 11.0 & 1.352 & 2.028 & 2.300 & 2.705 & 10.144 \\
\hline 3 & 10.2 & 1.112 & 1.690 & 2.203 & 2.705 & 8.115 \\
\hline 4 & 9.0 & 0.909 & 1.352 & 1.352 & 2.300 & 7.100 \\
\hline 5 & 8.0 & 0.676 & 1.217 & 1.352 & 2.029 & 5.072 \\
\hline 6 & 7.0 & 0.672 & 1.082 & 0.811 & 1.691 & 4.733 \\
\hline
\end{tabular}

Table 3. Experimental values of axial thrust, $P$ measured at 167 RPM for different diameter drills and work materials

\begin{tabular}{|c|c|c|c|c|c|c|}
\hline \multirow{2}{*}{$\begin{array}{c}\text { S. } \\
\text { No. }\end{array}$} & \multirow{2}{\text{Drill}}{$\begin{array}{c}\text { Dia. } \\
\text { (in } \mathbf{m m} \text { ) }\end{array}$} & Axial thrust, $\boldsymbol{P}$ (in $\boldsymbol{N}$ ) for different work materials \\
\cline { 3 - 7 } & Brass & $\begin{array}{c}\text { Alum- } \\
\text { inium }\end{array}$ & $\begin{array}{c}\text { Cast } \\
\text { iron }\end{array}$ & $\begin{array}{c}\text { Mild } \\
\text { steel }\end{array}$ & Copper \\
\hline 1 & 12.0 & 774.1 & 877.2 & 1032.0 & 1651.5 & 1033.2 \\
\hline 2 & 11.0 & 748.3 & 877.2 & 980.5 & 1393.4 & 1032.2 \\
\hline 3 & 10.2 & 722.5 & 722.3 & 980.5 & 1238.6 & 980.6 \\
\hline 4 & 9.0 & 567.6 & 619.3 & 825.8 & 1135.3 & 877.2 \\
\hline 5 & 8.0 & 516.1 & 619.2 & 774.2 & 1083.8 & 774.1 \\
\hline 6 & 7.0 & 516.1 & 567.6 & 774.1 & 1083.8 & 774.1 \\
\hline
\end{tabular}

Table 4. Experimental values of torque, $M$ measured at 167 RPM for different diameter drills and work materials

\begin{tabular}{|c|c|c|c|c|c|c|}
\hline \multirow{2}{*}{$\begin{array}{c}\text { S. } \\
\text { No. }\end{array}$} & \multirow{2}{*}{$\begin{array}{c}\text { Drill } \\
\text { Dia. } \\
\text { (in } \mathbf{m m} \text { ) }\end{array}$} & \multicolumn{4}{|c|}{ Torque, $\boldsymbol{M}$ (in $\boldsymbol{N}$ - $\boldsymbol{m}$ ) for different work materials } \\
\hline 1 & 12.0 & 3.381 & $\begin{array}{c}\text { Alum- } \\
\text { inium }\end{array}$ & $\begin{array}{c}\text { Cast } \\
\text { iron }\end{array}$ & $\begin{array}{c}\text { Mild } \\
\text { steel }\end{array}$ & Copper \\
\hline 2 & 11.0 & 2.705 & 2.840 & 2.840 & 6.086 & 5.680 \\
\hline 3 & 10.2 & 2.029 & 2.840 & 2.651 & 6.086 & 5.410 \\
\hline 4 & 9.0 & 2.029 & 2.028 & 2.434 & 5.680 & 5.086 \\
\hline 5 & 8.0 & 1.217 & 1.623 & 2.246 & 5.275 & 4.733 \\
\hline 6 & 7.0 & 0.811 & 1.623 & 1.840 & 4.057 & 4.056 \\
\hline
\end{tabular}


Table 5. Neural network prediction (values) of axial thrust, $P$ at 110 RPM for different diameter drills and work materials

\begin{tabular}{|c|c|c|c|c|c|c|}
\hline \multirow{2}{*}{$\begin{array}{c}\text { S. } \\
\text { No. }\end{array}$} & $\begin{array}{c}\text { Drill } \\
\text { Dia. } \\
\text { (in } \mathbf{m m} \text { ) }\end{array}$ & \multicolumn{4}{|c|}{ Axial thrust, $\boldsymbol{P}$ (in $\boldsymbol{N}$ ) for different work materials } \\
\cline { 3 - 7 } & Brass & $\begin{array}{c}\text { Alum- } \\
\text { inium }\end{array}$ & $\begin{array}{c}\text { Cast } \\
\text { iron }\end{array}$ & $\begin{array}{c}\text { Mild } \\
\text { steel }\end{array}$ & Copper \\
\hline 1 & 12.0 & 984.1 & 899.5 & 1495.2 & 1090.6 & 1239.0 \\
\hline 2 & 11.0 & 773.1 & 775.9 & 1030.8 & 1065.4 & 1188.2 \\
\hline 3 & 10.2 & 773.0 & 775.2 & 904.3 & 1030.3 & 1130.2 \\
\hline 4 & 9.0 & 618.2 & 725.7 & 875.9 & 1003.7 & 1080.3 \\
\hline 5 & 8.0 & 540.3 & 725.7 & 770.0 & 992.5 & 1033.7 \\
\hline 6 & 7.0 & 460.7 & 700.3 & 722.0 & 981.5 & 1032.2 \\
\hline
\end{tabular}

Table 6. Neural network prediction (values) of torque, $M$ at 110 RPM for different diameter drills and work materials

\begin{tabular}{|c|c|c|c|c|c|c|}
\hline \multirow{2}{*}{$\begin{array}{c}\text { S. } \\
\text { No. }\end{array}$} & \multirow{2}{*}{$\begin{array}{c}\text { Drill } \\
\text { Dia. }\end{array} \mathbf{m m}$ ) } & \multicolumn{6}{|c|}{ Torque, $\boldsymbol{M}$ (in $\boldsymbol{N}$-m ) for different work materials } \\
\cline { 3 - 7 } & Brass & $\begin{array}{c}\text { Alum- } \\
\text { inium }\end{array}$ & $\begin{array}{c}\text { Cast } \\
\text { iron }\end{array}$ & $\begin{array}{c}\text { Mild } \\
\text { steel }\end{array}$ & Copper \\
\hline 1 & 12.0 & 2.003 & 2.281 & 2.350 & 2.875 & 9.234 \\
\hline 2 & 11.0 & 1.551 & 2.029 & 2.216 & 2.721 & 8.226 \\
\hline 3 & 10.2 & 1.100 & 1.722 & 2.156 & 2.229 & 7.009 \\
\hline 4 & 9.0 & 0.922 & 1.361 & 1.360 & 2.032 & 5.966 \\
\hline 5 & 8.0 & 0.687 & 1.220 & 1.344 & 2.001 & 5.001 \\
\hline 6 & 7.0 & 0.661 & 1.090 & 0.823 & 1.778 & 4.562 \\
\hline
\end{tabular}

Table 7. Neural network prediction (values) of axial thrust, $P$ at 167 RPM for different diameter drills and work materials

\begin{tabular}{|c|c|c|c|c|c|c|}
\hline \multirow{2}{*}{$\begin{array}{c}\text { S. } \\
\text { No. }\end{array}$} & $\begin{array}{c}\text { Drill } \\
\text { Dia. } \\
\text { (in } \mathbf{m m} \text { ) }\end{array}$ & \multicolumn{4}{|c|}{ Axial thrust, $\boldsymbol{P}($ in $\boldsymbol{N}$ ) for different work materials } \\
\cline { 3 - 7 } & Brass & $\begin{array}{c}\text { Alum- } \\
\text { inium }\end{array}$ & $\begin{array}{c}\text { Cast } \\
\text { iron }\end{array}$ & $\begin{array}{c}\text { Mild } \\
\text { steel }\end{array}$ & Copper \\
\hline 1 & 12.0 & 772.5 & 872.5 & 1028.2 & 1650.2 & 1028.2 \\
\hline 2 & 11.0 & 768.1 & 871.2 & 978.4 & 1328.4 & 1028 \\
\hline 3 & 10.2 & 720.2 & 728.1 & 972.8 & 1236.3 & 982.6 \\
\hline 4 & 9.0 & 562.6 & 618.3 & 824.5 & 1132.2 & 879.3 \\
\hline 5 & 8.0 & 515.2 & 617.3 & 784.2 & 1082.8 & 772.6 \\
\hline 6 & 7.0 & 514.2 & 565.8 & 771.4 & 1080.4 & 770.28 \\
\hline
\end{tabular}

Table 8. Neural network prediction (values) of torque, $M$ at 167 RPM for different diameter drills and work materials

\begin{tabular}{|c|c|c|c|c|c|c|}
\hline \multirow{2}{*}{$\begin{array}{c}\text { S. } \\
\text { No. }\end{array}$} & \multirow{2}{*}{$\begin{array}{c}\text { Drill } \\
\text { Dia. } \\
\text { (in } \mathbf{m m} \text { ) }\end{array}$} & \multicolumn{4}{|c|}{ Torque, $\boldsymbol{M}$ (in $\boldsymbol{N}$-m ) for different work materials } \\
\cline { 3 - 7 } & $\begin{array}{c}\text { Alum- } \\
\text { inium }\end{array}$ & $\begin{array}{c}\text { Cast } \\
\text { iron }\end{array}$ & $\begin{array}{c}\text { Mild } \\
\text { steel }\end{array}$ & Copper \\
\hline 1 & 12.0 & 3.28 & 3.72 & 3.62 & 6.96 & 6.26 \\
\hline 2 & 11.0 & 2.82 & 2.72 & 3.42 & 6.21 & 5.98 \\
\hline 3 & 10.2 & 2.41 & 2.68 & 3.14 & 6.02 & 5.63 \\
\hline 4 & 9.0 & 2.18 & 2.21 & 2.74 & 5.62 & 5.32 \\
\hline 5 & 8.0 & 1.12 & 1.62 & 2.65 & 5.18 & 4.83 \\
\hline 6 & 7.0 & 1.01 & 1.62 & 2.23 & 4.13 & 4.15 \\
\hline
\end{tabular}

\section{RESULTS}

The comparison of measured values of cutting forces through rigorous experimentation and those predicted by neural network are shown in Fig. 5 to 8.

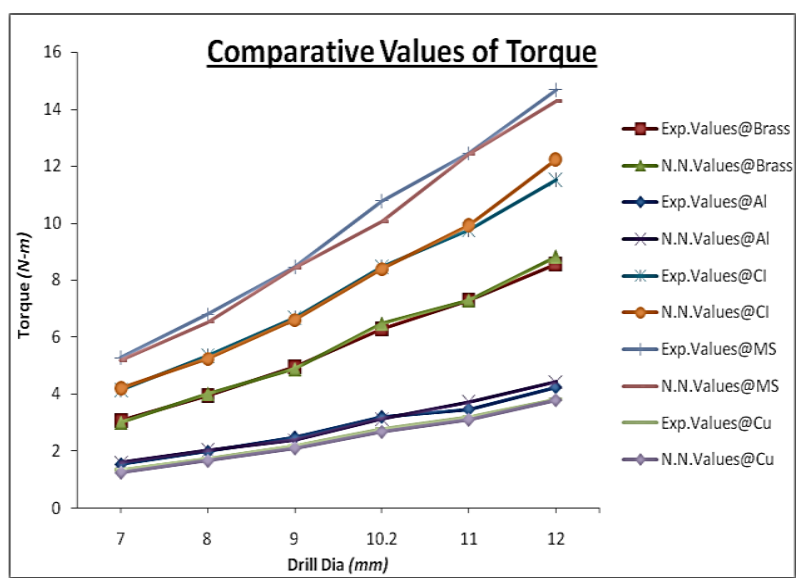

Fig 5: Comparison between Experimental and NN values of torque, $M$ at 110 RPM for different diameter drills and work materials

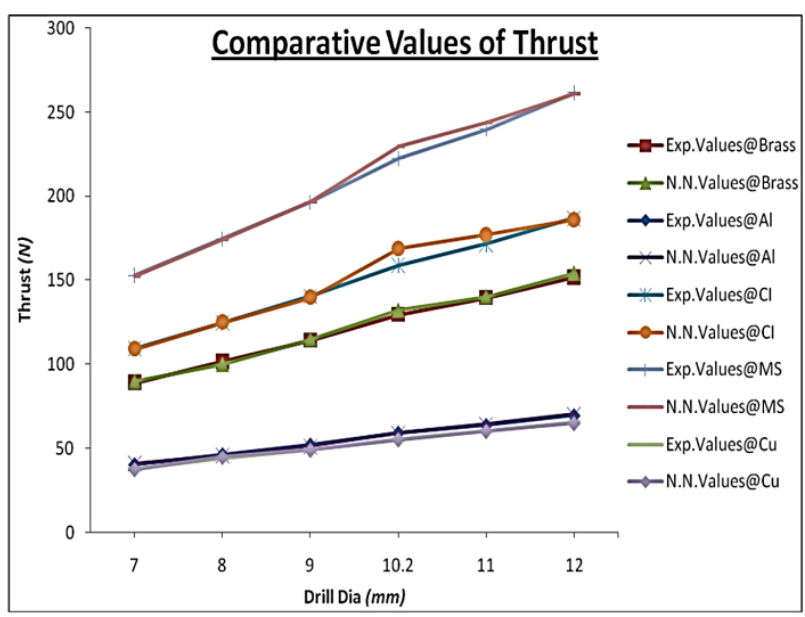

Fig 6: Comparison between Experimental and NN values of axial thrust, $P$ at 110 RPM for different diameter drills and work materials

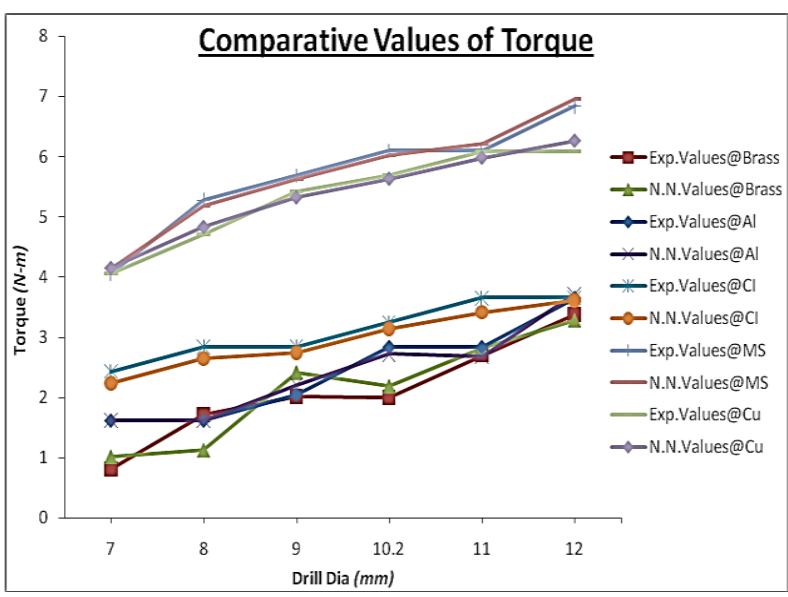

Fig 7: Comparison between Experimental and NN values of torque, $M$ at 167 RPM for different diameter drills and work materials 


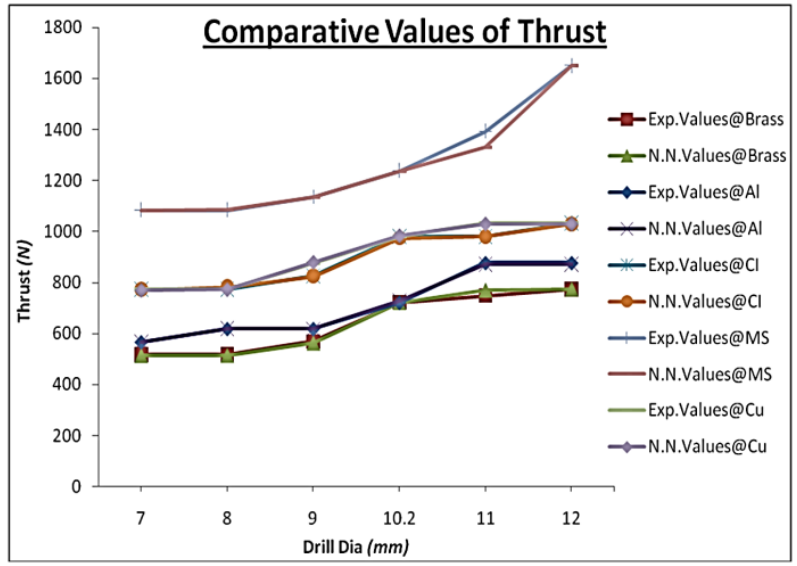

Fig 8: Comparison between Experimental and NN values of axial thrust, $P$ at 167 RPM for different diameter drills and work materials

\section{CONCLUSION}

Whenever, the cutting force estimation problem in Drilling machine arises, it is possible to give the initial loading to this trained neural network model and it can give a fairly good estimation of corresponding forces torque and axial thrust values. Thus, there is an advantage of not using the machine tool if the torque and axial thrust forces are beyond the limits of the machine tool. The comparison of measured values of cutting forces through rigorous experimentation and those predicted by neural network confirms the cutting forces, viz., torque and axial thrust.

\section{ACKNOWLEDGMENT}

The authors gratefully acknowledge the inspiration provided by the Most Revered Prof. P.S. Satsangi Sahab, Chairman, Advisory Committee on Education, Dayalbagh, Agra.

\section{REFERENCES}

[1] Kronenberg, M., 1966. Machining Science and Applications. Oxford: Pergamon Press.

[2] Kasilova, A.G. and Mescheryakov, R.K., 1985. Technological Machining Handbook. Englewood Cliffs, NJ: Prentice Hall.

[3] Rao, P.N., 2000. Manufacturing Technology. New Delhi, India: Tata McGraw-Hill.

[4] Groover, M.P., 2007. Fundamentals of Modern Manufacturing. USA: John Wiley and Sons.

[5] Fausett, L., 1994. Fundamentals of Neural Networks. Eaglewood Cliffs, NJ: Prentice Hall.

[6] More, J.J., 1977. The Levenberg - Maquardt Algorithm. G.A. Watson ed. Lecture Notes in Mathematics, Springer-Verlag, 630, 105-116.

[7] Aggarwal A. and Singh H., 2005. Optimization of machining techniques $-\mathrm{A}$ retrospective and literature review. Sadhana, 30 (6), 699-711.

[8] Merchant, M.E., 1998. Interpretive look at $20^{\text {th }}$ century research on modeling of machining. Machining Science and Technology, 2 (2), 157-163.
[9] Osman, M.O.M., Xistris, G.D. and Chahil G.S., 1979. The measurement and stochastic modelling of torque and thrust in twist drilling. Interntional Journal of Production Research, 17 (4), 359-376.

[10] Koplev, A., Lystrup, Aa. and Vorm, T., 1983. The cutting process, chips and cutting forces in machining CFRP. Composites, 14 (4), 371-376.

[11] Veniali, F., Di Llio, A. and Tagliaferri, V., 1995. An experimental study of the drilling of aramid composites. Journal of Energy Resources Technology, 117 (4), 271278.

[12] Fuh, K.-H. and Wang, S.-B., 1997. Force modeling and forecasting in creep feed grinding using improved BP neural network. International Journal of Machine Tools and Manufacture, 37 (8), 1167-1178.

[13] Lee, B.Y., Liu, H.S. and Tarng, Y.S., 1998. Modeling and optimization of drilling process. Journal of Materials Processing Technology, 74 (1-3), 149-157.

[14] Szecsi, T., 1999. Cutting force modeling using artificial neural networks. Journal of Materials Processing Technology, 92-93, 344-349.

[15] Elhachimi, M., Torbaty, S. and Joyot, P., 1999. Mechanical modelling of high speed drilling I: predicting torque and thrust. International Journal of Machine Tools and Manufacture, 39 (4), 553-568.

[16] Lachaud, F., Piquet, R., Collombet, F. and Surcin, L., 2001. Drilling of composite structures. Composite Structures, 52 (3-4), 511-516.

[17] Ramulu, M., Branson, T. and Kim, D., 2001. A study on the drilling of composite and titanium stacks. Composite Structures, 54 (1), 67-77.

[18] Zuperl, U. and Cus, F., 2004. Tool cutting force modeling in ball-end milling using multilevel perceptron. Journal of Materials Processing Technology, 153-154, 268-275.

[19] Sheng, Y. and Tomizuka, M., 2006. Intelligent modeling of thrust force in drilling process. Journal of Dynamic Systems, Measurement, and Control, 128 (4), 846-855.

[20] Abrão, A.M., Faria, P.E., Campos Rubio, J.C., Reis, P. and Paulo Davim, J., 2007. Drilling of fiber reinforced plastics: A review. Journal of Materials Processing Technology, 186 (1-3), 1-7.

[21] Aykut, Ş., Gölcü, M., Semiz, S. and Ergür, H.S., 2007. Modelling of cutting forces as function of cutting parameters for face milling of stellite 6 using artificial neural network. Journal of Materials Processing Technology, 190 (1-3), 199-203.

[22] Tsao, C.C. and Hocheng, H., 2008. Evaluation of thrust force and surface roughness in drilling composite material using Taguchi analysis and neural network. Journal of Materials Processing Technology, 203 (1-3), 342-348. 
[23] Gilbert, W.W., 1950. Economics of machining. In Machining - Theory and practice. Transactions of American Society for Metals, 476-480.

[24] Armarego, E.J.A. and Brown, R.H., 1969. The Machining of Metals. Englewood Cliffs, NJ: Prentice Hall.

[25] Singh, R., Das, G. and Setia, R., 2007. Parametric modeling of a rotary furnace for agile production of castings with artificial neural networks. International Journal of Agile Manufacturing, 10 (2), 137-147.
[26] Singh, R., Setia, R. and Das, G., 2007. Modeling and optimization of rotary furnace parameters using artificial neural networks and genetic evolutionary algorithms. In Proceedings of the $31^{\text {st }}$ National Systems Conference, Manipal, India, P.No. 75.

[27] Brewer, R.C. and Rueda, R., 1963. A simplified approach to the optimum selection of machining parameters. Eng. Dig., 24(9), 133-150.

[28] Ai, X. and Xiao, S., 1985. Metal Cutting Condition Handbook. China: Mechanics Industry Press. 